\title{
Em cena no Teatro do Bairro Alto: A familia Schroffenstein
}

\author{
Maria Helena Serôdio
}

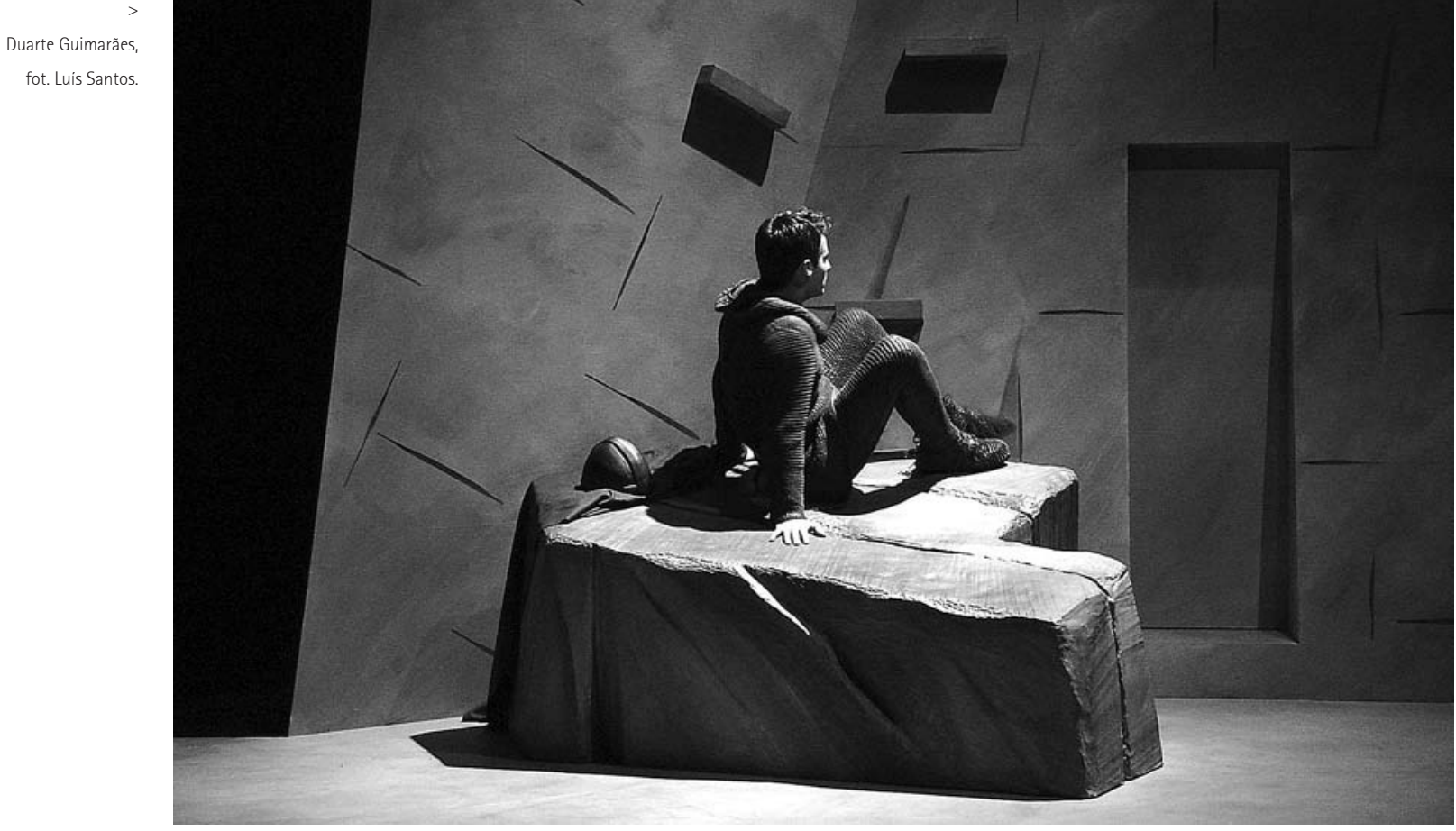

Titulo: A família Schroffenstein (1801). Autor: Heinrich von Kleist. Tradução: João Barrento. Encenação: Luís Miguel Cintra. Cenários e figurinos: Cristina Reis. Desenho de luzes: Daniel Worm d'Assumpção. Som:Vasco Pimentel com Hugo Reis. Interpretação: Catarina Requeijo, Dinis Gomes, Duarte Guimarães, Glicinia Quartin João Lizardo, João Pedreiro, José Manuel Mendes, Luís Lima Barreto, Luis Lucas, Luis Miguel Cintra, Manuel Romano, Márcia Breia, Ricardo Aibéo, Rita Durão, Rita Loureiro. Produção: Teatro da Cornucópia. Local e data de estreia: Teatro do Bairro Alto, 24 de Junho de 2004.

Não é fácil dizer o patronímico que a peça nomeia - tão germanófilo nos soa -, nem se espera que hoje em dia uma peça eleja a "familia" como matéria dramatizável e, ainda por cima, a privilegie no título (vai longe a história da Família Trapp....). Mas era justamente por isso que o desafio começava por se instalar, cansados que estamos de títulos "cintilantes", colhidos na conversa quotidiana, vagamente prometendo cenas agitadas ou deleitosas, como vem sendo prática em algumas narrativas recentes. A diferença, então, em primeiro lugar.

Depois, havia a memória de outros títulos que a Cornucópia tratara cenicamente, como a peça de Jakob Lenz

${ }^{1}$ Sobre as várias encenaçōes das peças de Kleist em Portugal, consultar a CETbase em - O novo Menoza, ou a História do Príncipe Tandi de Cumba - numa interessantíssima solução teatral, que encantou quantos a viram. E há ainda aquela já conhecida e incessante procura de textos e autores canónicos, que a companhia empreende, para transfigurar em cena, vivificando de maneira muitas vezes feliz mundos ficcionais com que vamos convivendo no patamar mais desinquieto das nossas memórias. Nem sempre, porém, a escolha recai sobre as peças mais emblemáticas, como faz aquele que procura os esconsos dos haveres literários, na esperança de ser surpreendido por alguma coisa esquecida e que pode constituir uma revelação: para quem a procura e para quem depois a lerá (ou verá em palco).

Por outro lado, a deriva do romantismo animara já alguns trabalhos da companhia, com particular destaque para Almeida Garrett (Um auto de Gil Vicente) ou Hölderlin (A morte de Empédocles). Então Heinrich von Kleist, romântico de vida atormentada e que se suicidara relativamente jovem (aos 34 anos), seria uma escolha possivel à luz desse interesse, quer para focalizar o seu fascínio pelo lado obscuro da psique, quer para citar o seu credo idealista, a sua crença rousseauista - na bondade humana contra a perfídia da sociedade. Desse autor já foram encenadas em Portugal peças como A bilha quebrada e 0 principe de Homburgo', e 
narrativas como 0 terramoto no Chile e Michael Kohlhaas tiveram já admiráveis recriações cénicas: a primeira pelo Teatro do Mundo, em 1981 sob a direcção de Michel Mathieu; a segunda, em 1997, pelos Artistas Unidos, com reescrita de Jorge Silva Melo e interpretada de maneira melancolicamente esfuziante por Paulo Claro no espectáculo Num país onde não querem defender os meus direitos, eu não quero viver.

Com tradução de João Barrento, o texto de Kleist, que a Cornucópia agora levou à cena, é a primeira peça do autor, e localiza a aç̧ão num ambiente medieval de castelos, envolvendo amores proibidos e cavaleiros que se repartem entre a defesa indefectível da justiça e a mais truculenta vontade de vingança. A família, que o título nomeia, dividese entre os que habitam o castelo de Rossitz (onde vive Roberto) e o de Warwand (onde mora Silvestre), e entre estes dois ramos da familia instala-se a desconfiança (que, porém, se provará infundada): em ambas as casas morrera um dos filhos e, como por "contrato" se decidira em tempos que, não havendo descendência num dos lados, o outro herdaria tudo (bens e poder), a dúvida de que a(s) morte(s) terá (terão) sido planeada(s) ameaça a paz entre os dois ramos da familia. 0 espectáculo abre então ao som de uma missa de "corpo" presente em que Roberto obriga a mulher e os filhos a jurarem vingança sobre todos os de Warwand, construindo deste modo um quadro que simultaneamente evoca uma atmosfera e subverte alguns dos valores a ela associados. Assim, de um lado, a música solene do órgão e a comunhão da família enlutada, mas, ao mesmo tempo, o coro de vozes - femininas e masculinas - que, de fora de cena, alternadamente, vão citando as razões do ódio, e legitimando a litania da vingança.

Os figurinos, de Cristina Reis, sinalizam vestes de cavaleiros aprumados e damas recatadas (como imaginariamente os fomos inventando numa Idade Média fantasiosa), mas a sua policromia - onde haverá, ao lado da gradação de cinzentos, grenás e castanhos -, contrastava com a moldura que cenograficamente Cristina Reis concebera e que operava especialmente sobre o preto e o cinzento (embora a cor azul dominasse a luz do ciclorama). Era uma moldura assimétrica atravessada de traços que sinalizavam fragmentariamente ogivas, frestas e muros de pedra, em desenho de assumido esquematismo. Só na segunda parte desceria da teia uma barra vermelha em ziguezague que atravessaria a cena toda para figurar o desacerto trágico final (como um raio que desce tempestuosamente à terra). À direita, uma "rocha" onde se encontram os enamorados - Otto (filho de Roberto) e Inês (filha de Silvestre) -, bem como uma espécie de torre a cuja alta janela se acede por ressaltos de pedras. Neste desenho simples, que parecia resumir importantes traços arquitectónicos de igreja, castelo ou gruta, funcionavam de forma perfeita as cortinas escuras que deslizavam nos dois sentidos (da esquerda para a direita e vice-versa) para as passagens de cena, permitindo pequenas - e, todavia, muito eloquentes - mudanças de cenário. Do lado de Roberto o altar, o pequeno caixão (com a figura em gesso) e a cadeira de espaldar alto; na casa de Silvestre a pequena mesa familiar e a caixa dos brinquedos (com miniaturas de cavaleiros e peões). Esta diferença era acentuada pela crispação e agressividade no papel de Roberto, que Luis Miguel Cintra interpretava de forma apaixonada num primeiro tempo, e pelo tom mais cordato, de estreme bonomia, que Luís Lima Barreto imprimia à figura de Silvestre. Simetria em contraponto estava também nas mulheres de ambos: Eustáquia, a compadecida mulher de Roberto, atormentada pela violência que a rodeia, era trazida à cena com acertada sensibilidade por Rita Loureiro, enquanto Gertrudes, mulher de Silvestre e meia-irmã de Eustáquia, surgia como a prosaica mulher, linguareira e desconfiada, que Márcia Breia sublinhava com singular - e muito própria - exuberância.

Não é dificil perceber no destino dos jovens enamorados Inês e Otto a história infeliz de Romeu e Julieta. Mas o mais curioso é a redundância de citações shakespearianas - frases literais e situações dramáticas - com que Kleist emoldura os amores funestos de Verona, aqui transpostos para a Suábia: o velho Silvio, avô de Inês, sugere Lear (José Manuel Mendes num belo perfil, próximo de Ran, de Kurosawa), e expressamente repete (as palavras de Gloucester) de como vão infelizes os tempos em que os loucos guiam os cegos, recolhendo mais tarde em seus braços Inês, qual Cordelia, morta; fala-se do "cadáver que tresanda" a propósito de João, desta feita citando Hamlet na sua diatribe a propósito de Polonius; vemos ainda na mistela que a jovem camponesa Barnabé agita no caldeirão (onde se inclui o dedo mindinho que cortara ao menino afogado) reminiscências das maquinações das feiticeiras de Macbeth; e lemos ainda uma semelhança entre o final da peça de Ricardo II, com a cínica atitude de Bolingbroke perante a notícia do assassinato de Ricardo, e a frieza com que Roberto deixa que uma "fúria popular", encenada a comando seu, mate o nobre Jerónimo, e, perante a sofrida indignação da mulher, acaba por mandar executar o primeiro que o atingiu, provocando o maior desespero entre aqueles que mais não fizeram do que cumprir as ordens suas; por último, a circunstância de Otto e Inês que, tendo trocado de fatos entre si, acabam assassinados pelos próprios pais, recorda o caso de Henrique VI (3. ${ }^{\text {P Parte) }}$ em que, na discórdia civil entre lorques e Lencastres, um filho mata o próprio pai e um pai mata o próprio filho no campo de batalha, em ambas as cenas percebendo-se a mesma denúncia de como a violência recai sobre quem a pratica.

É legítimo ler na história - recamada de alusões literárias e declarações piedosas - a referência metafórica à vida na sua exasperada conflitualidade, bem como à ideia de que o poder corrompe. Com efeito, veja-se a hipocrisia com que os mandantes poderosos "condenam" publicamente os cúmplices que executam as suas ordens, mas a quem prometem prebendas se acatarem a pena (certamente a ser revogada em breve) e se mantiverem o silêncio.

Se a fábula desta peça de Kleist - na sua linha evolutiva - revela evidentes sinais de tragédia, a verdade é que, citando o modo romântico, há traços de ironia na história, o que Luis Miguel Cintra trabalha de forma deliberada no espectáculo em dois sentidos: quer provocando o riso em duas ou três cenas, quer exagerando o artifício. No primeiro caso, a 
discussão entre Silvestre e Gertrudes a propósito de um possivel "envenenamento" daquele, provocado pelos de Rossitz (mas de que, afinal, só ela poderia ser culpada, porque foram os frutos dela que ele comera), ou o breve apontamento sobre a sineta que um dos serviçais dá a Roberto para evitar o assobio com que os chama (e que, aparentemente, põe os cães em alvoroço). No segundo caso, de excesso de teatralidade, é sobretudo a cena na gruta: a convergência de todos no mesmo lugar, os equivocos entre os dois corpos por causa da troca da roupa, os assassínios (rápidos e eficientes) e a posterior promessa de reconciliação, com Roberto e Silvestre lado a lado a declararem um perdão em que ninguém acredita. A cena evoca o desenlace, temido e desejado, e integra-se naquele projecto de arte que acredita na possibilidade de regenerar almas. Ora o espectáculo, que Cintra encenou, detém-se justamente nessa "exibição" (foregrounding, diriam os estruturalistas), como se de uma citação estética se tratasse. E essa pode ter sido uma das razões de alguma incomodidade na recepção do espectáculo: por um lado, parecia haver uma colagem às doutrinas românticas que, na história e nas ideias, a peça colocava, por outro, havia momentos em que a pequena fenda da ironia permitia o jogo da desconstrução. 0 melodrama surge então como teatral, assumindo-se o palco como o lugar da sua perfeita enunciação.

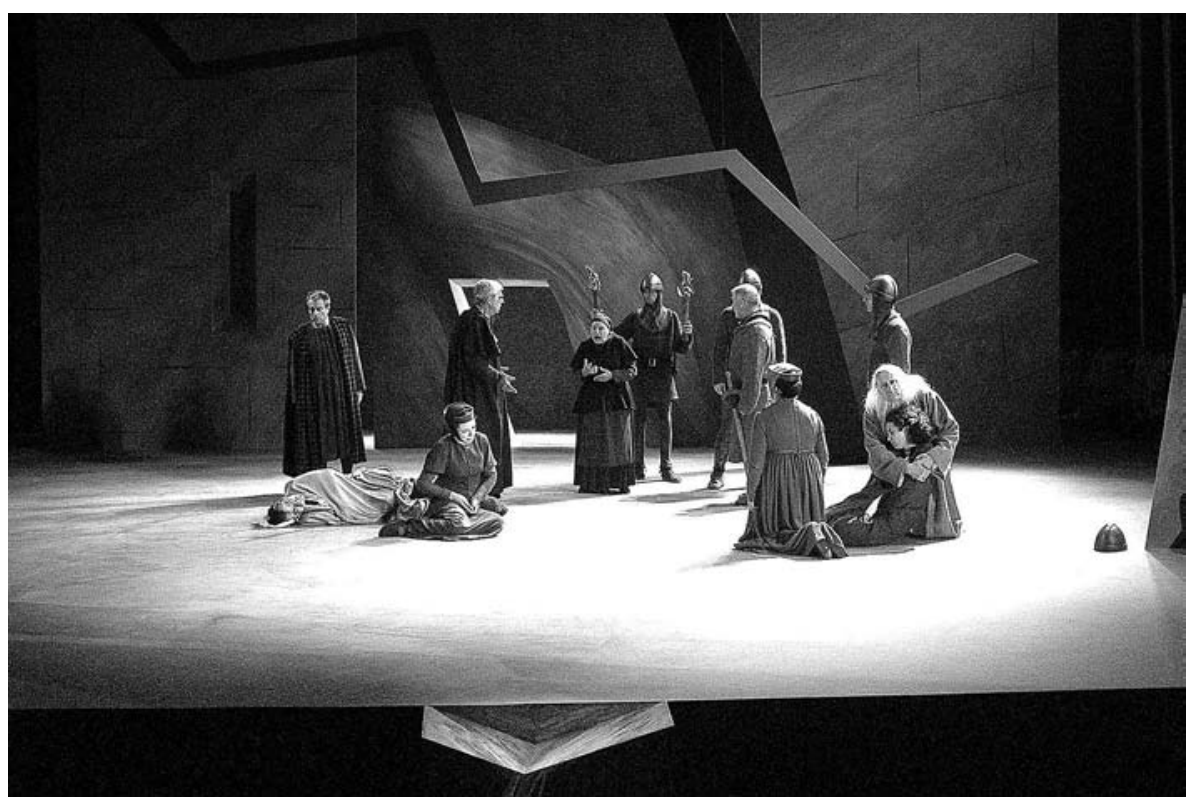

Se a polaridade dos dois casais emerge como o jogo da idade adulta nos seus cambiantes de desconfiança, ódio e impossibilidade de (re)aprenderem o amor, é no casal jovem de Otto e Inês que se centra a exposição da inocência ainda não contaminada pelo mal do mundo. E, na sua figuração, Rita Durão e Duarte Guimarães dão-nos interpretações vivas, veementes, belíssimas de juventude e alegria. Nos dois outros jovens também enamorados de Inês - João, meio irmão de Otto, e Jerónimo, um outro Schroffenstein - vemos, no primeiro caso (que João Lizardo interpreta), o amor não correspondido transformar-se em loucura, e, no segundo (que Ricardo Aibéo presentifica), a cavaleiresca renúncia que, acompanhada de uma vontade de reconciliação das duas partes da família, valer-lhe-á ser assassinado a mando de Roberto.

Contando com um elenco de 15 actores, o espectáculo foi também a evidência de uma política artistica e repertorial que só é possível no contexto de uma relativa estabilidade, como a Cornucópia (entre outras companhias) tem sabido preservar com tenacidade. E daí nos vem o equilibrio de uma arte que se joga no plano individual, mas que se escora também nas relações que vão sendo forjadas num caminho comum e que são para nós, espectadores, um horizonte de expectativa que desejamos ver cumprido. Por isso é bom rever Glicínia Quartin em cena, na breve mas calorosa aparição de Úrsula, viúva de um coveiro e mãe da jovem Barnabé (que Catarina Requeijo representa), ou ouvir a voz clara e serena de Luís Lucas nas três figuras que traz ao palco, enquanto Dinis Gomes revela um crescente domínio de cena num perfil frágil que vai animando num jogo de efémeros protestos.

Efabulações, enfim, que a Cornucópia tece com a arte de muitos. 